\title{
III - Impacto econômico das causas externas no Brasil: um esforço de mensuração
}

\author{
III - Economic impact of external causes in Brazil: \\ an attempt at measurement
}

\author{
Roberto F. Iunes \\ Departamento de Epidemiologia da Faculdade de Saúde Pública da Universidade de São Paulo. São \\ Paulo, SP - Brasil
}

\begin{abstract}
Resumo
Procurou-se obter uma primeira estimativa do impacto econômico das lesões e envenenamentos no Brasil, medido através dos gastos hospitalares com internação - dias de permanência geral e em Unidades de Terapia Intensiva. São analisadas internações em hospitais conveniados com o Sistema Único de Saúde, através das AIH- Autorização de Internação Hospitalar, sendo verificado que essas internações geram um gasto anual, correspondendo a, aproximadamente, 0,07 do Produto Interno Bruto do País. Com relação à mortalidade, o impacto econômico foi analisado por meio do indicador Anos Potenciais de Vida Perdidos. Os acidentes e violências representaram cerca de 2,6 milhões de anos de vida perdidos, em 1981, e 3,4 milhões, em 1991. O aumento verificado foi cerca de $30 \%$, enquanto que para o conjunto de dados os óbitos apresentaram-se em queda. Apesar de algumas limitações, é possível estimar a dimensão geral do impacto econômico das causas externas. Espera-se que essas limitações sirvam de estímulo a novas investigações e aprofundamentos.
\end{abstract}

Ferimentos e lesões, economia. Envenenamento, economia. Mortalidade hospitalar.

\begin{abstract}
The study seeks to make a first estimate of the economic impact of lesions and poisonings in Brazil, measured in terms of hospital expenses on internments - in days of general permanence and in Intensive Care U nits. Internments is hospital under contracts with the $U$ nited Health System are analysed by means of the AlH - Authorization for $\mathrm{H}$ ospital Internment. These internments involve expenses per annum corresponding to approximately $0.07 \%$ of the GN P of the country. With regard to mortality, the economic impact has been analysed by the use of the Potential Years of Life Lost indicator. It may be verified that accidents and acts of violence represented about 2.6 million years of life lost in 1981, and 3.4 millions in 1991. The increase was thus of about $30 \%$, even though for the total of data deaths showed a reduction. Despite some limitations, itis possible to estimate the general magnitude of the economic impact of external causes of death. It is hoped that these limitations may serve as a stimulus to new and deeper investigations.
\end{abstract}

Wounds and injuries, economy. Poisoning, economy. H ospital mortality. 


\section{INTRO DUÇÃO}

Os acidentes e violências como causa de mortalidade e morbidade têm atingido proporções quase epidêmicas no Brasil, conforme salientado nas Partes I e II da presente publicação. São incipientes, no entanto, os esforços para se tentar estimar o seu impacto econômico no Brasil (Iunes ${ }^{3}, 1994$ e Ugá7, 1994).

Conceitualmente, o custo econômico introduzido por uma doença, ou problema de saúde, pode ser classificado em duas grandes categorias: os chamados custos diretos e custos indiretos (Hodgson e Meiners $^{2}$, 1982). Os primeiros referem-se aos custos (médicos e não-médicos) relacionados ao diagnóstico, tratamento, recuperação e reabilitação da doença. Os custos diretos médicos são, obviamente, aqueles impostos por ações e prescrições médicas. Incluem-se aí os custos de exames e procedimentos diagnósticos, consultas, internações, reabilitação, e outros. Os custos com transporte e locomoção para tratamento, diagnóstico e reabilitação, com dietas especiais, com mudanças por motivos ambientais como clima e qualidade do ar, são exemplos de elementos que compõem os custos diretos não-médicos impostos por uma doença. Enquanto os custos médicos recaem, necessariamente, sobre o paciente, na estimação dos custos não-médicos deve-se considerar os custos impostos a terceiros, como parentes e acompanhantes. Seriam, por exemplo, computados entre os custos não-médicos, os custos de transporte da mãe que acompanha a criança ao médico.

Os custos indiretos referem-se à perda de produção e produtividade trazidas pela doença ou problema de saúde, como a perda de dias de trabalho, e a menor produtividade gerada por limitações físicas ou psicológicas. Assim como no caso dos custos diretos não-médicos, os custos indiretos devem ser estimados considerando-se também o impacto do problema de saúde sobre outras pessoas além do próprio paciente. Seguindo-se o mesmo exemplo utilizado acima, seriam considerados parte dos custos indiretos, os dias de trabalho perdidos pela mãe para acompanhar a criança ao médico e/ou estar com ela em casa ou no hospital. No que se refere ao paciente em particular, os custos indiretos podem ser causados por morbidade ou mortalidade. Nos casos de in- capacidade permanente ou mortalidade, consideramse todos os anos (ou dias) potenciais de vida e de trabalho perdidos.

Pode-se agregar à análise do custo econômico da doença, uma terceira categoria de custos: aqueles comumente definidos como psicossociais ou intangíveis. Tais custos devem refletir o impacto psicossocial trazido por um problema de saúde. Como, por definição, a sua mensuração é difícil (ou mesmo impossível), estes custos são freqüentemente excluídos dos trabalhos. As doenças fatais ou incapacitantes, por exemplo, trazem consigo um custo psicológico importante que,evidentemente, não se limita à pessoa afetada pelo problema, mas atinge terceiros como familiares e amigos. Poder-se-ia até mesmo especular que, nestes casos, os custos psicossociais seriam os mais importantes. O caso da AIDS é um exemplo singular de uma doença que implica em custos psicossociais extermamente elevados, não apenas por se tratar de uma doença fatal, mas também por toda a carga de estigma e discriminação que ela ainda, infelizmente, traz consigo. Historicamente, a hanseníase poderia ser também vista como uma doença com custo psicossocial elevado*.

Embora não caiba no presente trabalho uma discussão conceitual mais detalhada das limitações metodológicas presentes na estimativa de custo econômico da doença, é evidente que essas limitações são significativas. As críticas mais severas dirigemse à mensuração dos custos indiretos, onde a utilização do valor do trabalho, como medida de custo, implicaria não apenas a definição de uma dimensão monetária à vida humana, mas também uma discriminação negativa para com as mulheres, crianças e velhos, para não falar na mão-de-obra menos qualificada**. A alternativa freqüentemente utilizada para minimizar tais problemas é a de não se assinar valores monetários aos custos indiretos, mas apenas estimá-los como anos potenciais de vida perdidos (APVP).

O presente trabalho procura obter uma primeira estimativa do impacto econômico das lesões e envenenamentos no Brasil. Não se busca estimar os custos dos acidentes e violências, já que tais dados não estão disponíveis no País***. Na verdade, uma análise deste tipo exigiria o desenvolvimento de um traba-

\footnotetext{
* Parcela dos custos psicossociais pode estar sendo captada nas outras duas categorias: as visitas a vários médicos diferentes, a busca de métodos alternativos, a queda acentuada na produtividade e as mudanças freqüentes de trabalho ou residência podem ser indicadores de um problema de saúde com custo psicossocial elevado.

** Algumas destas críticas apresentam mais fundamento do que outras. No entanto, independentemente de tal fato, elas revelam uma larga resistência em aceitar tais medidas.

*** Lesões e envenenamentos e acidentes e violência estão sendo usados alternativamente para designar os mesmos casos. Mais rigorosamente, lesões e envenenamentos referem-se a internações cujas causas são acidentes e violências.
} 
lho de campo e a elaboração de uma metodologia específica que permitisse a comparação e agregação das informações obtidas.

Assim, as estimativas aqui apresentadas visam apenas indicar o sentido e a dimensão geral de algumas das categorias de custo econômico descritas acima, para o caso das lesões e envenenamentos.

\section{MATERIAL E MÉTO DO}

Os dados de "Movimentação de Autorização de Internação Hospitalar" do Sistema Único de Saúde (SUS) são a base para as estimativas de gastos hospitalares e servem como indicador da dimensão dos custos médicos diretos*. A mesma fonte de dados permite uma aproximação dos dias perdidos devido à morbidade hospitalar.

Conforme já ressaltado na Parte II da presente publicação, as informações obtidas através das fichas de Autorização de Internação Hospitalar (AIH) trazem dados importantes, mas apresentam algumas limitações significativas:

i. estão limitadas aos hospitais cadastrados junto ao SUS;

ii. não incorporam os atendimentos nas emergências (pronto-socorros) que, no caso dos acidentes e violências, podem representar um volume considerável de recursos;

iii. os hospitais públicos tendem a subfaturar e, portanto, subnotificar suas internações. Esta limitação será tão mais importante quanto maior for o peso relativo das internações por acidentes e violências em tais hospitais, vis-à-vis os hospitais da rede privada;

iv. do ponto de vista econômico os dados fornecidos pela AIH refletem valores reembolsados pelo SUS, ou seja, fixados exogenamente (arbitrariamente). Neste sentido, os valores absolutos e os pesos relativos dos diversos componentes da AIH estão muito mais relacionados com limitações orçamentárias do que com a estrutura de custos do procedimento. O mesmo ocorre com os preços relativos dos diversos procedimentos;

v. fraudes e abusos podem distorcer os dados.

Estão, portanto, excluídos dos cálculos, os gastos relativos a procedimentos diagnósticos, terapêuticos e de reabilitação não executados durante a internação, ou em hospitalizações fora da rede conveniada com o SUS. Podese dizer que, na verdade, os dados aqui apresentados fornecem uma descrição do custo das causas externas para o governo federal.
A mortalidade por causas externas e os dias perdidos por internação hospitalar indicam a grandeza dos custos indiretos impostos pelos acidentes e violências. Os dados de mortalidade foram obtidos a partir das estatísticas de mortalidade publicadas pelo Ministério da Saúde ${ }^{5}$. As informações disponíveis para a estimativa do que poderia ser chamado de custo indireto não permitem calcular a perda de produção e produtividade, bem como os custos dos dias perdidos por incapacidade (permanente ou temporária).

Assim, embora a profundidade da análise esteja limitada pelas restrições acima descritas, as informações disponíveis permitem conhecer a dimensão geral do impacto econômico dos acidentes e violências. Afinal, as internações do SUS cobrem algo entre $77,5 \%$ e $83,5 \%$ das internações hospitalares ocorridas no País (Iunes $\left.{ }^{4}, 1995\right)$ e a mortalidade, parcela mais importante dos APVP, estão presentes nos cálculos.

Os dados apresentados dizem respeito ao mês de novembro de 1994, não considerado como mês atípico (conforme já referido), e foram obtidos do "CD-ROM" ${ }^{6}$ " fornecido pelo DATASUS.

\section{RESU LTAD O S E DISCU SSÃO}

\section{- G astos H ospitalares}

As Tabelas 1 e 2 apresentam algumas características gerais das internações por lesões e envenenamentos, para as grandes regiões e para o País como um todo. A Tabela 1 mostra o número de internações, os dias de permanência geral e em unidades de terapia intensiva (UTIs), bem como os gastos (expressos em reais de novembro de $1995^{* *}$ ), distribuídos entre diversos itens de despesa realizados para reembolsar tais internações***. A Tabela 2 mostra a participação destes números no total das internações.

Como se pode ver, em novembro de 1994 foram 72.766 internações por lesões e envenamentos em toda a rede conveniada com o SUS, o que representa $5,8 \%$ do total de internações****. Esse total é diferente daquele apresentado na Parte II (73.357), visto que aquele inclui os casos em que havia um traumatismo somente no diagnóstico secundário. Conforme apontado nessa mesma Parte, os números relativos ao mês de novembro não apresentam nenhuma indicação de que sejam atípicos e, portanto, podem ser utilizados para projetar valores anuais $* * * * *$.

\footnotetext{
* Os dados de internação hospitalar foram obtidos a partir do Sistema Integrado de Tratamento Estatístico de Séries Estratégicas (SÍNTESE), desenvolvido pelo Ministério da Saúde/DATASUS e de CD-Rom (novembro/94) distribuído pelo SUS.

** O valor do Real, no ano de 1995, estava ao par do dólar.

*** Os valores foram inflacionados para novembro de 1995 utilizando-se o Índice Geral de Preços - Disponibilidade Interna (IGP-DI), publicado pela Fundação Getúlio Vargas.

**** Estão presentes nas tabelas apenas aqueles casos em que as lesões e envenenamentos aparecem como disgnóstico primário.

***** Note que as internações por causas externas representaram 5,8\% do total das internações do SUS ao longo de todo 1994 (ver a Tabela 1 da parte II desta publicação).
} 
Tabela 1 - Dados sobre internações por lesões e envenenamentos. Brasil e regiões, novembro de 1994.

\begin{tabular}{lrrrrrr}
\hline Dados & Norte & Centro-O este & Nordeste & Sudeste & Sul & Brasil \\
\hline Número de casos & 4.479 & 4.878 & 17.905 & 35.081 & 10.423 & 72.766 \\
Dias UTI & 220 & 1.150 & 1.738 & 6.675 & 3.370 & 13.153 \\
Dias permanência & 22.550 & 27.542 & 88.571 & 186.169 & 54.131 & 378.963 \\
Tempo médio intern. (dias) & 5,03 & 5,65 & 4,95 & 5,31 & 5,19 & 5,21 \\
Gastos (R de N ov. 1995) & & & & & & \\
Serv. hospitalares & $628.369,51$ & $1.013 .440,42$ & $3.133 .945,62$ & $7.072 .418,87$ & $2.609 .790,55$ & $14.457 .964,97$ \\
Serv. profissionais & $288.522,66$ & $411.704,42$ & $1.408 .229,67$ & $2.865 .925,34$ & $998.599,71$ & $5.972 .981,80$ \\
SADT* & $48.046,37$ & $81.489,86$ & $219.825,13$ & $592.162,36$ & $219.894,02$ & $1.161 .417,74$ \\
Taxas & $123.586,98$ & $162.471,85$ & $549.074,27$ & $1.123 .372,92$ & $394.840,82$ & $2.353 .346,84$ \\
Materiais/M edicamentos & $441.313,88$ & $601.705,04$ & $1.946 .727,32$ & $3.839 .900,21$ & $1.276 .999,43$ & $8.106 .645,88$ \\
UTI & $20.391,20$ & $103.697,66$ & $169.539,81$ & $620.164,45$ & $332.704,22$ & $1.246 .497,34$ \\
Permanência maior & $18.606,69$ & $31.937,38$ & $86.149,04$ & $187.774,36$ & $59.323,98$ & $383.791,46$ \\
Órteses e próteses & $23.305,55$ & $135.800,20$ & $297.875,04$ & $1.199 .255,71$ & $418.646,60$ & $2.074 .883,09$ \\
Sangue & $4.080,88$ & $26.660,52$ & $31.603,48$ & $134.987,19$ & $59.282,27$ & $256.614,34$ \\
\hline Total** & $992.324,98$ & $1.669 .095,42$ & $5.091 .478,93$ & $11.864 .749,47$ & $4.306 .213,15$ & $23.923 .861,94$ \\
Gasto médio & 221,55 & 342,17 & 284,36 & 338,21 & 413,15 & 328,78 \\
\hline
\end{tabular}

Fonte: Ministério da Saúde ${ }^{6}, 1995$.

O bs.: * Serviços Auxiliares Diagnóstico-Terapêuticos.

** Serv. H ospitalares+Serv. Profissionais+SADT+Ó rteses e Próteses+Sangue.

Valores corrigidos pelo IG P-DI da Fundação Getúlio Vargas.

O valor do Real, no ano de 1995, estava ao par do dólar.

As Tabelas 1 e 2 mostram também que as internações por causas externas tendem a ser mais dispendiosas do que a média das hospitalizações pagas pelo SUS: embora representem 5,8\% das internações, as lesões e envenamentos consomem $8 \%$ dos gastos totais do SUS, ou aproximadamente R\$ 24 milhões mensais, o que projeta um gasto anual de R\$ 287 milhões. Assim, enquanto o SUS paga em média $\mathrm{R} \$ 239,40$ por cada internação, as hospitalizações por causas externas custaram, em média, cerca de $37 \%$ a mais, ou $\mathrm{R} \$ 328,78^{*}$. Pode-se ver também, a partir das Tabelas, que as internações geradas por acidentes e violências tendem a ser relativamente mais caras em quase todos os itens de gasto e, em particular, como poder-se-ia esperar, no que se refere a órteses e próteses.

As internações por lesões e envenenamentos representam uma proporção relativamente menor do total de dias de hospitalização pagas pelo SUS (tempo médio de internação de 5,2 dias, comparado com 6,1 dias para todas as causas). A combinação deste dado, com o maior custo médio da internação, indica que as hospitalizações causadas por acidentes e violências apresentam um custo/dia significativamente (60\%) maior que a média geral dos casos: $\mathrm{R} \$ 63,11$ comparados com $\mathrm{R} \$ 39,44$, o que sugere hospitalizações de casos mais agudos e que, portanto, tendem a consumir recursos de maneira mais intensiva.
Esta percepção é corroborada quando se observa que, segundo os dados das AIHs, praticamente $70 \%$ das internações devido a lesões e envenenamentos são classificadas como cirúrgicas, enquanto essa proporção é de $22,6 \%$ para o total das hospitalizações.

A Tabela 1 mostra que as lesões e envenenamentos geraram pouco mais de 13.000 dias de internação em unidades de terapia intensiva (UTI) no País como um todo, no mês de novembro de 1994 (em um total de quase 379.000 dias de internação), ou cerca de 158.000 dias de UTI ao ano. Esses dias de UTI refletiram-se em um gasto de $\mathrm{R} \$ 1,2$ milhões naquele mês. Os gastos com serviços hospitalares, por sua vez, chegaram a aproximadamente $\mathrm{R} \$ 14,5$ milhões; as despesas com serviços profissionais, $\mathrm{R} \$ 6$ milhões; os gastos com exames e serviços diagnósticos consumiram R $\$ 1,2$ milhões; o pagamento de taxas hospitalares foi pouco superior a $\mathrm{R} \$ 2,3$ milhões; as internações por lesões e envenenamentos impuseram ao SUS um gasto de R \$ 8,1 milhões em materiais e medicamentos; o SUS pagou também, em novembro, um adicional de cerca de $\mathrm{R} \$ 384.000$ por aquelas internações de maior duração; o gasto com órteses e próteses chegou a $\mathrm{R} \$ 2$ milhões e com sangue a quase $\mathrm{R} \$ 257.000,00$.

No que se refere às diferentes regiões do País, os dados da Tabela 2 parecem ser relativamente estáveis. As exceções mais marcantes aparecem na

\footnotetext{
* Uma análise mais detalhada dos dados mostra que os vários itens de gasto apresentam uma distribuição bastante assimétrica - médias significativamente maiores que as medianas e estas maiores que as modas - indicando uma concentração de gastos em valores menores e um número relativamente pequeno de casos, deslocando os valores médios para cima. De maneira geral, as médias estão próximas do terceiro quartil da distribuição dos casos.
} 
Tabela 2 - Participação percentual no total de internações por lesões e envenenamentos. Brasil e regiões, novembro de 1994.

\begin{tabular}{|c|c|c|c|c|c|c|}
\hline Dados & Norte & Centro- $\mathrm{O}$ este & Nordeste & Sudeste & Sul & Brasil \\
\hline Número de casos & 6,16 & 5,94 & 4,93 & 6,55 & 5,41 & 5,84 \\
\hline Dias UTI & 10,53 & 7,96 & 6,22 & 9,28 & 8,06 & 8,31 \\
\hline Dias permanência & 7,42 & 5,88 & 4,63 & 4,98 & 4,78 & 5,01 \\
\hline Tempo médio interm. (dias) & 120,47 & 98,93 & 93,75 & 76,01 & 88,44 & 85,85 \\
\hline \multicolumn{7}{|l|}{ Gastos (R\$ de N ov. 1995) } \\
\hline Serv. hospitalares & 7,49 & 6,63 & 8,15 & 6,52 & 6,29 & 6,82 \\
\hline Serv. profissionais & 8,58 & 9,41 & 11,33 & 10,02 & 9,52 & 10,08 \\
\hline SADT* & 9,15 & 7,67 & 6,55 & 8,52 & 7,03 & 7,73 \\
\hline Taxas & 5,66 & 4,67 & 3,72 & 3,89 & 4,26 & 4,02 \\
\hline Materiais e medicamentos & 7,68 & 6,38 & 5,47 & 6,25 & 5,28 & 5,94 \\
\hline UTI & 10,90 & 8,03 & 6,43 & 9,01 & 7,78 & 8,16 \\
\hline Permanência maior & 20,31 & 11,59 & 11,63 & 12,66 & 11,21 & 12,30 \\
\hline Ó rteses e próteses & 33,72 & 16,79 & 19,16 & 18,90 & 18,67 & 18,83 \\
\hline Sangue & 10,35 & 8,87 & 8,68 & 10,43 & 8,84 & 9,61 \\
\hline Total** & 8,02 & 7,65 & 9,34 & 7,83 & 7,42 & 8,02 \\
\hline Gasto médio & 130,06 & 128,68 & 189,24 & 119,56 & 137,26 & 137,34 \\
\hline
\end{tabular}

Fonte: Ministério da Saúde ${ }^{6}, 1995$.

O bs.: * Serviços Auxiliares Diagnóstico-Terapêuticos.

** Serv. Hospitalares+Serv. Profissionais+SADT+Ó rteses e Próteses+Sangue.

região Norte com os gastos em órteses e próteses e com permanência maior. As lesões e envenenamentos $(6,2 \%$ do total de casos) representam $33 \%$ do gasto total do SUS com órteses e próteses na região e $20 \%$ do desembolso regional para o pagamento de permanências maiores. Pode-se ver também que, contrariamente ao observado nas demais regiões, no Norte do País os pacientes internados por causas externas ficam hospitalizados mais tempo (20\% a mais) do que a média geral dos pacientes. Finalmente, chama a atenção também o fato de que, no Nordeste, a internação média causada por acidentes e violências custa ao SUS $89 \%$ a mais do que a média das internações, enquanto no País como um todo essa diferença está, conforme mencionado acima, em $37 \%$.*

A Tabela 3 apresenta a distribuição regional dos dados presentes na Tabela 1 . No que se refere ao total das internações, a distribuição regional segue de maneira bastante próxima à própria distribuição populacional, o que era de se esperar, já que as quotas de AIH são distribuídas por critérios populacionais. Fica evidente, no entanto, a relativa concentração da prestação de serviços hospitalares por lesões e envenenamentos na região Sudeste: essa região (42,65\% da população do País) foi responsável por cerca de $48 \%$ das internações ocorridas por tais causas. O Sudeste também é responsável por mais de 50\% dos dias em UTI. Em função da já mencionada grande proporção de gastos com órteses e próteses e com permanência maior, observada para as causas externas da região Norte, a participação relativa da região nos gastos com tais itens de despesa é significativamente maior do que o esperado. Como a Tabela 3 mostra, na região Norte as despesas com órteses e próteses são aproximadamente $0,6 \%$ do total e as despesas com permanência, maior, $2,9 \%$. Já para as internações por lesões e envenenamentos, estas proporções chegam a $1,1 \%$ e $4,85 \%$, respectivamente.

A Tabela 4 apresenta a proporção dos dias em UTI no total de dias de permanência hospitalar, e a participação percentual de cada um dos componentes de gasto na despesa total com hospitalização. A Tabela mostra estes dados para o total das internações e para as admissões por lesões e envenenamentos.

Pode-se ver claramente que as hospitalizações decorrentes de causas externas apresentam uma proporção maior de dias em UTI do que o total das internações: os dias em UTI representam 3,5\% do total de dias de permanência hospitalar por lesões e envenenamentos, enquanto essa proporção é cerca de $40 \%$ menor (ou seja, $2,1 \%$ ) no total das internações. As regiões Sul e Sudeste, em particular, apresentam uma proporção grande de dias de UTI em casos de lesões e envenamentos. Essa maior utiliza-

\footnotetext{
* No que se refere às singularidades encontradas na região Norte, elas poderiam ser explicadas, feito um exame mais detalhado dos dados, pela estrutura da oferta e demanda por serviços de saúde da região. Já para o custo médio (relativo) maior, observado no Nordeste, as informações disponíveis não permitem a elaboração de qualquer conjectura.
} 
Tabela 3 - Dados gerais de internações por todas as causas e internações por lesões e envenenamentos, por regiões, novembro de 1994.

\begin{tabular}{|c|c|c|c|c|c|}
\hline & Norte & Centro- 0 este & Nordeste & Sudeste & Sul \\
\hline Dados & \multicolumn{5}{|c|}{ Internações por todas as causas } \\
\hline Número de casos & 5,83 & 6,59 & 29,12 & 43,00 & 15,46 \\
\hline Dias UTI & 1,32 & 9,13 & 17,65 & 45,48 & 26,42 \\
\hline Dias permanência & 4,02 & 6,20 & 25,33 & 49,49 & 14,97 \\
\hline \multicolumn{6}{|l|}{ Gastos } \\
\hline Serviços hospitalares & 3,96 & 7,21 & 18,14 & 51,14 & 19,56 \\
\hline Serviços profissionais & 5,67 & 7,38 & 20,97 & 48,27 & 17,71 \\
\hline SADT* & 3,49 & 7,08 & 22,34 & 46,26 & 20,83 \\
\hline Taxas & 3,73 & 5,95 & 25,22 & 49,27 & 15,83 \\
\hline M ateriais e medicamentos & 4,21 & 6,91 & 26,10 & 45,05 & 17,73 \\
\hline UTI & 1,23 & 8,46 & 17,25 & 45,07 & 28,00 \\
\hline Permanência maior & 2,94 & 8,83 & 23,73 & 47,54 & 16,96 \\
\hline Ó rteses e próteses & 0,63 & 7,34 & 14,11 & 57,58 & 20,35 \\
\hline Sangue & 1,48 & 11,26 & 13,64 & 48,49 & 25,13 \\
\hline Total** & 4,15 & 7,32 & 18,28 & 50,81 & 19,44 \\
\hline Dados & \multicolumn{5}{|c|}{ Internações por lesões e envenenamentos } \\
\hline Número de casos & 6,16 & 6,70 & 24,61 & 48,21 & 14,32 \\
\hline Dias UTI & 1,67 & 8,74 & 13,21 & 50,75 & 25,62 \\
\hline Dias permanência & 5,95 & 7,27 & 23,37 & 49,13 & 14,28 \\
\hline \multicolumn{6}{|l|}{ Gastos } \\
\hline Serviços hospitalares & 4,35 & 7,01 & 21,68 & 48,92 & 18,05 \\
\hline Serviços profissionais & 4,83 & 6,89 & 23,58 & 47,98 & 16,72 \\
\hline SADT* & 4,14 & 7,02 & 18,93 & 50,99 & 18,93 \\
\hline Taxas & 5,25 & 6,90 & 23,33 & 47,74 & 16,78 \\
\hline Materiais e medicamentos & 5,44 & 7,42 & 24,01 & 47,37 & 15,75 \\
\hline UTI & 1,64 & 8,32 & 13,60 & 49,75 & 26,69 \\
\hline Permanência maior & 4,85 & 8,32 & 22,45 & 48,93 & 15,46 \\
\hline Ó rteses e próteses & 1,12 & 6,54 & 14,36 & 57,80 & 20,18 \\
\hline Sangue & 1,59 & 10,39 & 12,32 & 52,60 & 23,10 \\
\hline Total & 4,15 & 6,98 & 21,28 & 49,59 & 18,00 \\
\hline
\end{tabular}

Fonte: Ministério da Saúde ${ }^{6}, 1995$.

Obs.: * Serviços Auxiliares Diagnóstico-Terapêuticos.

** Serv. Hospitalares+Serv. Profissionais+SADT+Ó rteses e Próteses+Sangue. UTI - Unidade de Tratamento Intensivo.

ção das UTIs no Sul e Sudeste pode ser interpretada como conseqüência de casos relativamente mais graves, ou como resultado da maior oferta desse tipo de recurso existente nessas áreas do País.

No que se refere à composição dos gastos, a Tabela 4 mostra que os materiais e medicamentos, e as taxas hospitalares em particular, representam uma proporção menor do gasto total no caso das lesões do que no total das internações: neste último caso, as taxas hospitalares chegam a atingir valores que representam quase $20 \%$ do gasto total do SUS. Já nas internações decorrentes de causas externas, esta proporção não chega a $10 \%$. A maior participação das órteses e próteses no gasto total das lesões e envenenamentos pode ser considerada como esperada.

A Tabela 5 apresenta um quadro sumário dos gastos anuais com internações por lesões e envenamentos. Os acidentes e violências geram um gasto hospitalar no SUS que pode ser estimado em pouco mais de $\mathrm{R} \$ 287.000 .000,00$ ao ano (ou algo em torno de 0,07\% do Produto Interno Bruto do País). Desse total, aproximadamente $\mathrm{R} \$ 173,5$ milhões $(60 \%$, como mostra a Tabela 4) destinam-se ao pagamento dos serviços hospitalares (diárias e taxas), a remuneração de profissionais implica em gasto de quase R $\$ 72 \mathrm{mi}-$ lhões (25\% do total), exames e serviços diagnósticos, R\$ 14 milhões (5\%), órteses e próteses, R\$ 25 milhões (9\%), e sangue, R\$ 3 milhões (1\%). A Tabela mostra, também, a participação desses itens no gasto total com internações. Conforme discutido na seção anterior, os dados da Tabela 5 servem como indicação preliminar dos custos médicos diretos impostos pelos acidentes e violências no País.

\section{- Anos Potenciais de Vida Perdidos}

A Tabela 6 mostra o número de óbitos causados por acidentes e violências e o número total de óbitos para 1981 e 1991, assim como suas respectivas 
Tabela 4 - Dados gerais de internações por todas as causas e internações por lesões e envenenamentos. Participação dos dias de UTI no total de dias de internação e dos itens de gasto no total de despesas hospitalares. Brasil e regiões, novembro de 1994.

\begin{tabular}{|c|c|c|c|c|c|c|}
\hline & Norte & Centro- 0 este & Nordeste & Sudeste & Sul & Brasil \\
\hline Dados & \multicolumn{6}{|c|}{ Internações por todas as causas } \\
\hline Dias UTI & 0,69 & 3,08 & 1,46 & 1,92 & 3,69 & 2,09 \\
\hline Dias de permanência & 100,00 & 100,00 & 100,00 & 100,00 & 100,00 & 100,00 \\
\hline \multicolumn{7}{|l|}{ Gastos } \\
\hline Serviços hospitalares & 67,73 & 70,00 & 70,53 & 71,51 & 71,49 & 71,06 \\
\hline Serviços profissionais & 27,15 & 20,05 & 22,79 & 18,87 & 18,09 & 19,86 \\
\hline SADT* & 4,24 & 4,87 & 6,15 & 4,58 & 5,39 & 5,03 \\
\hline Taxas & 17,65 & 15,95 & 27,09 & 19,03 & 15,99 & 19,63 \\
\hline Materiais e medicamentos & 46,41 & 43,19 & 65,27 & 40,53 & 41,68 & 45,71 \\
\hline UTI & 1,51 & 5,92 & 4,83 & 4,54 & 7,37 & 5,12 \\
\hline Permanência maior & 0,74 & 1,26 & 1,36 & 0,98 & 0,91 & 1,05 \\
\hline Ó rteses e próteses & 0,56 & 3,71 & 2,85 & 4,19 & 3,87 & 3,69 \\
\hline Sangue & 0,32 & 1,38 & 0,67 & 0,85 & 1,16 & 0,89 \\
\hline Total & 100,00 & 100,00 & 100,00 & 100,00 & 100,00 & 100,00 \\
\hline Dados & \multicolumn{6}{|c|}{ Internações por lesões e envenenamentos } \\
\hline Dias UTI & 0,98 & 4,18 & 1,96 & 3,59 & 6,23 & 3,47 \\
\hline Dias permanência & 100,00 & 100,00 & 100,00 & 100,00 & 100,00 & 100,00 \\
\hline \multicolumn{7}{|l|}{ Gastos } \\
\hline Serviços hospitalares & 63,32 & 60,72 & 61,55 & 59,61 & 60,61 & 60,43 \\
\hline Serviços profissionais & 29,08 & 24,67 & 27,66 & 24,15 & 23,19 & 24,97 \\
\hline SADT* & 4,84 & 4,88 & 4,32 & 4,99 & 5,11 & 4,85 \\
\hline Taxas & 12,45 & 9,73 & 10,78 & 9,47 & 9,17 & 9,84 \\
\hline M ateriais e medicamentos & 44,47 & 36,05 & 38,24 & 32,36 & 29,65 & 33,89 \\
\hline UTI & 2,05 & 6,21 & 3,33 & 5,23 & 7,73 & 5,21 \\
\hline Permanência maior & 1,88 & 1,91 & 1,69 & 1,58 & 1,38 & 1,60 \\
\hline Ó rteses e próteses & 2,35 & 8,14 & 5,85 & 10,11 & 9,72 & 8,67 \\
\hline Sangue & 0,41 & 1,60 & 0,62 & 1,14 & 1,38 & 1,07 \\
\hline Total** & 100,00 & 100,00 & 100,00 & 100,00 & 100,00 & 100,00 \\
\hline
\end{tabular}

Fonte: Ministério da Saúde ${ }^{6}, 1995$.

Obs.: * Serviços Auxiliares Diagnóstico-Terapêuticos.

** Serv. Hospitalares+Serv. Profissionais+SADT+Ó rteses e Próteses+Sangue. UTI - U nidade de Tratamento Intensivo.

taxas de crescimento. Como se vê, as mortes por causas externas chegam a quase 102.000, em 1991, ou cerca de $12,1 \%$ do total de óbitos registrados no País, conforme foi visto na Parte I da presente publicação, enquanto em 1981 essa proporção era de $9,6 \%$. O problema da violência no País aparece de maneira bastante clara quando se observa que os óbitos por causas externas aumentaram em cerca de $42 \%$ entre 1981 e 1991, ou a uma taxa média anual de 3,6\%, enquanto o total de óbitos cresceu pouco menos de $13 \%$ no período (taxa média anual de $1,2 \%$ ). Ao longo destes 10 anos, o crescimento da população do País foi de $20,5 \%$, ou cerca de $1,9 \%$ ao ano.

A Tabela 7 apresenta os APVPs devido à mortalidade por causas externas e para o total de óbitos. $\mathrm{O}$ limite superior utilizado para os cálculos foi de 70 anos, padrão recomendado para o Brasil por BECKER e $\operatorname{col}^{1}$ (1989). Devido a limitações impostas pelas informações disponíveis, não foi possível utilizar o limite inferior de 7 dias sugerido pelos mesmos autores. Por esse motivo utilizou-se zero como limite inferior.

Conforme se verifica, a Tabela 7 mostra que a mortalidade por acidentes e violências representaram cerca de 2,6 milhões de anos de vida perdidos em 1981, e 3,4 milhões em 1991*. Ao longo dos onze anos compreendidos entre 1981 e 1991, o impacto das violências e acidentes, medido em APVP, aumentou em cerca de $30 \%$ (ou quase $2,7 \%$ ao ano). No entanto, para o total das causas observa-se uma diminuição no número de APVPs. Essa queda, de quase $12 \%$, observada em termos de APVP para o agregado da mortalidade, reflete uma importante (e po-

* Para o cálculo dos APVPs não foi utilizada nenhuma faxa de desconto. 
Tabela 5 - Dados sobre projeção de gastos anuais com internações por lesões e envenenamentos. Brasil, 1994. (R\$ de novembro, 1995).

\begin{tabular}{lrr}
\hline Tipo & Gastos anuais & \% sobre total de internações \\
\hline Serviços hospitalares & $173.495 .579,69$ & 6,82 \\
Serviços profissionais & $71.675 .781,59$ & 10,08 \\
SADT* & $13.937 .012,86$ & 7,73 \\
Taxas & $28.240 .162,08$ & 4,02 \\
Materiais e medicamentos & $97.279 .750,54$ & 5,94 \\
UTI & $14.957 .968,04$ & 8,16 \\
Permanência maior & $4.605 .497,55$ & 12,30 \\
Órteses e próteses & $24.898 .597,14$ & 18,83 \\
Sangue & $3.079 .372,06$ & 9,61 \\
\hline Total** & $287.086 .343,33$ & 8,02 \\
\hline
\end{tabular}

Fonte: Ministério da Saúde. Dados brutos.

Obs.: * Serviços Auxiliares Diagnóstico-Terapêuticos.

** Serviços Hospitalares+Serviços Profissionais+SADT+Ó rteses e Próteses+Sangue.

Valores corrigidos pelo IGP-DI, Fundação G etúlio Vargas.

O valor do Real, no ano de 1995, estava ao par do dólar.

Tabela 6 - Número de óbitos e taxas de crescimento, acidentes e violências e todas as causas. Brasil, 1981, 1991.

\begin{tabular}{|c|c|c|c|}
\hline \multicolumn{2}{|c|}{ Ó bitos e taxa de crescimento } & \multirow{2}{*}{$\begin{array}{c}\text { Acidentes e violências } \\
71.833\end{array}$} & \multirow{2}{*}{$\begin{array}{c}\text { Todas as causas } \\
750.276\end{array}$} \\
\hline N úmero de óbitos & 1981 & & \\
\hline & 1991 & 101.964 & 845.248 \\
\hline \multirow[t]{2}{*}{$\%$ sobre o total } & 1981 & 9,57 & 100,00 \\
\hline & 1991 & 12,06 & 100,00 \\
\hline \multirow{2}{*}{\multicolumn{2}{|c|}{$\begin{array}{l}\text { Taxa de crescimento 1981-1991 } \\
\text { M édia anual }\end{array}$}} & 41,95 & 12,66 \\
\hline & & 3,56 & 1,20 \\
\hline
\end{tabular}

Fonte: Ministério da Saúde. Dados brutos.

Tabela 7 - Número de anos potenciais de vida perdidos (APVP) por mortalidade por causas externas e todas as causas. Brasil, 1981, 1991.

\begin{tabular}{|c|c|c|}
\hline APVP & Acidentes e violências & Todas as causas \\
\hline Anos Potenciais de Vida Perdidos 1981 & $2.622 .160,50$ & $22.284 .905,50$ \\
\hline 1991 & $3.417 .264,00$ & $19.612 .310,00$ \\
\hline \multirow{2}{*}{$\%$ sobre o total } & 11,77 & 100,00 \\
\hline & 17,42 & 100,00 \\
\hline Taxa de crescimento 1981-1991 & 30,32 & $-11,99$ \\
\hline Média anual & 2,68 & $-1,27$ \\
\hline
\end{tabular}

Fonte: Ministério da Saúde. Dados brutos.

Tabela 8 - Número de anos potenciais de vida perdidos (APVP) por acidentes e violências. Brasil, 1981, 1991.

\begin{tabular}{lrr}
\hline APVP & \multicolumn{1}{c}{ APVP } & Distribuição \% \\
\hline Mortalidade* & $3.417 .264,00$ & 99,64 \\
Morbidade hospitalar** & $12.459,06$ & 0,36 \\
\hline Total & $3.429 .723,06$ & 100,00 \\
\hline
\end{tabular}

Fonte: Tabelas anteriores. Ver partes I e II desta publicação.

Obs.: * 1991

** 1994

sitiva) mudança na estrutura etária dos óbitos, deslocando-a de idades mais precoces para faixas etárias mais elevadas, onde o número de anos potenciais perdidos é, por definição, menor.

Embora representem cerca de $12 \%$ dos óbitos em 1991, os acidentes e violências representam 17,4\% dos anos potenciais de vida perdidos naquele ano.
Este é um resultado particularmente interessante por implicar que as mortes por acidentes e violências ocorrem, em média, em pessoas mais jovens do que o observado no quadro geral de óbitos do País. Isso ocorre mesmo se considerando que as causas externas atingem um contigente pequeno de crianças menores de 5 anos: o número de óbitos em crianças 
menores de 5 anos representa cerca de $16,8 \%$ do total de mortes em 1991, enquanto essa mesma proporção é de 3,4\% para as causas externas.

Os quase 379.000 dias de internação observados para as causas externas, em novembro de 1994, projetam cerca de 12.459 anos de vida perdidos por morbidade ao longo de 1994. A Tabela 8 apresenta o resultado final, mensurável a partir dos dados disponíveis para as causas externas, no que se refere aos APVPs potenciais de vida perdidos devido à mortalidade e morbidade (hospitalar). Como se vê, as causas externas implicam cerca de 3.430 .000 anos de vida perdidos ao ano.

\section{COMENTÁRIOS FINAIS}

As limitações de dados impedem um cálculo mais preciso dos custos impostos pelos acidentes e violências no Brasil. Pode-se, no entanto, a partir de informações de gastos hospitalares e de mortalidade, estimar a dimensão geral do impacto econômico das causas externas.

No que se refere aos chamados custos médicos diretos, os resultados obtidos mostram que as lesões e envenamentos são, não apenas, causa importante de internação hospitalar no País, mas também responsáveis por um gasto considerável por parte do governo federal. As projeções feitas estimam tais gastos em R \$ 287 milhões por ano. Esses valores não incluem os gastos em emergências (prontosocorro), as despesas com exames e serviços diagnósticos não realizados em nível de internação, além dos gastos com tratamentos ambulatoriais e reabilitação.

Se, por um lado, as internações por causas externas tendem a ser um pouco mais curtas do que a média dos casos, por outro lado tendem a consumir

\section{REFERÊN CIAS BIBLIO G RÁFICAS}

1. BECKER, R.A. et al. Investigação sobre perfis de saúde: Brasil, 1984. Brasília, Ministério da Saúde, 1989.

2. HODGSON, T.A. \& MEINERS, M.R. Cost-of-illness methodology: a guide to current practices and procedures. Milbank Mem. Fund. Q., 60: 429-62, 1982.

3. IUNES, R.F. The economic impact of violence on health care services: a case study of the city of São Paulo. S. Paulo, 1994. [Trabalho elaborado para a Organização Panamericana da Saúde/Organização Mundial da Saúde, 1994]. recursos de maneira mais intensiva. Como consequiência, apresentam um gasto/dia $60 \%$ superior à média geral das hospitalizações pagas pelo SUS.

No que se refere aos chamados custos indiretos das causas externas, os dados de mortalidade mostram um marcante crescimento entre 1981 e 1991, tanto no que se refere a números absolutos e relativos, quanto aos APVPs. O número de óbitos por causas externas cresceu $42 \%$ em dez anos, crescimento 3,3 vezes maior do que o observado para o total de mortes.

Mais marcante ainda é o fato de que enquanto o País experimenta, entre 1981 e 1991, uma queda de cerca de $12 \%$ no número de APVPs (considerandose todas as causas de morte), no caso particular dos acidentes e violências, este aumenta em $30 \%$ no mesmo período.

Não foi possível obter os gastos de seguros e programas de pensões para casos de acidentes e violências. Trata-se de um tópico importante de investigação a ser desenvolvido, já que se acredita que as informações que se fazem necessárias poderiam ser obtidas junto às instituições competentes, públicas e privadas. Dessa maneira, ter-se-ia uma idéia de um volume de recursos que se imagina importante, e que são desembolsados de maneira permanente pela sociedade.

Estão também ausentes no presente trabalho os custos monetários e as perdas, em termos de anos potenciais de vida, das incapacidades (temporárias e permanentes).

As limitações dos dados praticamente impedem um estudo mais aprofundado em termos de custos, bem como a incorporação de vários elementos particularmente importantes.

Espera-se que essas limitações aqui destacadas sirvam de estímulo a novas investigações e aprofundamentos.

4. IUNES, R.F. Impacto econômico do Diabetes Mellitus no Brasil: custos diretos e indiretos. São Paulo, 1995. [Trabalho elaborado para o Ministério da Saúde, em fase de publicação].

5. MINISTÉRIO DA SAÚDE. Estatísticas de mortalidade, 1981. Brasília, 1984

6. MINISTÉRIO DA SAÚDE. Fundação Nacional da Saúde. DATASUS. Movimento de autorização de internação hospitalar. Brasília, 1994. [CD-Rom].

7. UGÁ, M.A.D. Impacto económico de la violencia sobre los servicios de salud en países de América Latina y Caribe: el caso de Rio de Janeiro. São Paulo, 1994. [Trabalho elaborado para a Organização Panamericana da Saúde/Organização Mundial da Saúde]. 